\title{
CONSIDERAÇÕES SOBRE A EFICÁCIA DOS DIREITOS FUNDAMENTAIS NAS RELAÇÕES PRIVADAS
}

\section{CONSIDERATIONS ABOUT THE EFFECTIVENESS OF FUNDAMENTAL RIGHTS IN RELATIONS BETWEEN INDIVIDUALS}

\author{
${ }^{1}$ Camilla Martins Mendes Pereira
}

\section{RESUMO}

A presente pesquisa trata da vinculação dos particulares aos direitos fundamentais. $\mathrm{O}$ objetivo principal é traçar o desenvolvimento doutrinário a esse respeito e determinar as duas principais teorias existentes. Para tanto, utiliza-se como método de abordagem o dedutivo e como método de procedimento a pesquisa bibliográfica e o estudo comparativo para melhor compreender e a analisar o surgimento desta concepção da eficácia dos direitos fundamentais. Uma vez compreendido o porquê desta vinculação, volta-se para o problema central da temática, que é analisar os limites desta projeção dos direitos fundamentais. A conclusão obtida é que somente o caso concreto pode demandar qual a melhor teoria que dever ser aplicada.

Palavras-chave: Direitos fundamentais, Relações interprivadas, Eficácia horizontal

\begin{abstract}
This research deals with the application of the fundamental rights to relations between private individuals. The main objective is to trace the development of the theory about the effectiveness of these rights and to determine the two most important theories. For this, it is used the deductive method and the literature research and the comparative study to better understand and analyze the emergence of this conception of the effectiveness of the fundamental rights. Once understood this, it goes back to the central theme of the problem, which is to analyze the limits of the projection of fundamental rights. The result is that only the case will demand the correct theory that should be applied.
\end{abstract}

Keywords: Fundamental rights, Relations between individuals, Horizontal effectiveness

\footnotetext{
${ }^{1}$ Mestranda em Direito Público pela Faculdade de Direito da Universidade Federal de Uberlândia UFU, Uberlândia, Minas Gerais. E-mail: tutortreinamento@gmail.com
} 


\section{INTRODUÇÃO}

O presente trabalha analisará os fundamentados da existência de uma vinculação dos particulares aos direitos fundamentais no direito nacional, e quais as teorias que tratam do limite ou extensão dessa vinculação, a saber, se defendem que atingirão eficácia direta ou mediata, ou então eficácia indireta ou mediata.

A concepção clássica dos direitos fundamentais confina a sua aplicação às relações entre os indivíduos e o Estado. Originada no pensamento liberal burguês do século XVII e XVIII, essa concepção baseia-se na premissa de que o Estado é inimigo do homem e o poder a antítese do Direito.

Nesse contexto, para proteger o indivíduo do arbítrio estatal cria-se uma esfera de ingerência individual, a qual não pode ser atingida pelo Poder Público. Tal concepção se torna precária com o advento da sociedade de massas e do capitalismo global, em que despontam no meio social forças capazes de disputar com o Estado o monopólio do poder.

Assim, os direitos fundamentais passam a ser considerados multifuncionais, sendo dotados de uma função de defesa e outra de prestação. A função de defesa, de origem do pensamento liberal clássico, garante a defesa do indivíduo contra a interferência estatal. Por outro lado, a função de prestação exige uma postura ativa do Estado para garantir que estes direitos não sejam desrespeitados e devidamente efetivados.

Contudo, quando se trata do tema da vinculação dos particulares aos direitos fundamentais tem-se que esta não se dá com a mesma extensão e proteção em que se verifica na relação indivíduo-Estado. Assim sendo, o principal problema, que se propõe a doutrina, é qual o limite da vinculação dos particulares aos direitos fundamentais?

A Constituição Federal de 1988 não faz previsão expressa da vinculação dos particulares aos direitos fundamentais. Ainda assim, é possível observar por meio de levantamento bibliográfico da doutrina nacional e pelas decisões das cortes judiciais superiores, em destaque, do Supremo Tribunal Federal (RE 160.222/RJ e RE 201.819/RJ), que tal vinculação é cabível no ordenamento pátrio.

Contudo, quanto ao tipo de eficácia que estas normas serão dotadas, observa-se divergências doutrinárias. Pela teoria da eficácia indireta ou mediata a aplicação se dará por meio do esforço tanto do legislador, quanto do magistrado que por meio de suas atividades promoverão a aplicação dos direitos fundamentais pelo direito privado, atuando por meio de clausulas gerais ou conceitos jurídicos indeterminados. Pela teoria da eficácia direito ou 
imediata os direitos fundamentais são aplicados diretamente às relações privadas, independentemente de uma legislação específica ou clausulas gerais oriundas provenientes do direito privado.

Pode-se observar, portanto, que a utilização de uma ou outra teoria depende de uma análise específica do problema e de quais os pontos positivos e negativos de cada sistema e qual o melhor a ser aplicado no sistema jurídico nacional.

O objetivo da pesquisa é o debate sobre o tema da regulação das relações privadas sob parâmetros mínimos de respeito as direitos fundamentais e de proteção da dignidade humana. A esfera privada não trata de uma esfera de livre ofensa aos atributos mínimos de dignidade da pessoa humana.

Nesse contexto, busca-se uma aproximação entre a moral e o direito privado, assim como, definir critérios de como se processará essa aproximação e estabelecer as vantagens e desvantagens de cada teoria, que incorrem em paralelismo de visões ideológicas (liberalismo e intervencionismo). E, por fim, tem como fito evitar que se incorra num possível "panprincipiologismo" ou numa "panconstitucionalização" do direito privado.

O presente trabalho justifica-se uma vez que o ordenamento jurídico pátrio caminha no sentido de evitar que nas relações privadas hajam situações, que afastem o acesso dos sujeitos aos direitos básicos e à preservação da dignidade humana. Tal concepção leva a necessidade de uma análise profunda da questão da vinculação dos particulares aos direitos fundamentais.

A noção de que a autonomia privada não é absoluta e que os valores da dignidade humana devem ser respeitados mesmo no âmbito da relações intraindividuais perpassa por questões importantíssimas. Há a necessidade de ponderação da aplicação dos direitos fundamentais nesse tipo de relação, uma vez que, apresenta caracteres diversos da relação vertical do indivíduo com o Estado.

Acredita-se que o estudo da questão possa nortear a escolha do operador do direito que se defronte com situações semelhantes, e principalmente ordenar a atuação do judiciário, uma vez que, o Poder Público apresenta uma função negativa de abstenção de infringir os direitos fundamentais dos indivíduos (função de defesa) e também uma função positiva de garantir que estes sejam respeitados de quem quer os infrinjam, inclusive nas relações que se dão entre particulares.

O método utilizado no desenvolvimento do presente estudo será o método dedutivo. Com o estudo acerca da evolução da teoria geral dos direitos fundamentais irá se justificar a 
vinculação destes aos particulares, e posteriormente analisar quais os tipos de eficácia que serão dotados nesse tipo de relação.

Considera-se que o tema em debate é bastante amplo e tangencia uma séries de aspectos do direito constitucional contemporâneo, por isso não tem como objetivo demonstrar a necessidade e esmiuçar os prós e contra da projeção dos direitos fundamentais à esfera privada, mas sim compreender como se dá a sua origem no âmbito do constitucionalismo de princípios da sociedade pós moderna.

\section{EFICÁCIA HORIZONTAL DOS DIREITOS FUNDAMENTAIS}

Antes de se tratar propriamente da temática sobre a eficácia das normas de direitos fundamentais, insta tratar primeiramente da eficácia das normas jurídicas como gênero, para que possa-se compreender melhor a problemática ora em análise. Informa-se, que a pesquisa desenvolvida parte do método dedutivo e da análise teórica para que se possa compreender o fenômeno em tela.

\subsection{Plano da Eficácia das Normas Jurídicas}

A norma jurídica é uma proposição jurídica que contém a descrição de um fato, e este fato sofre uma regulação jurídica, a saber, antecedente e consequente. A norma jurídica se desenvolve nos planos do mundo jurídico, sendo estes divididos em: plano da existência, validade e eficácia.

O plano da existência é o plano do ser, não se cogita se a norma é válida ou não, eficaz ou não, o que importa é que a norma está posta e existe, mesmo que, não seja vigente. Sobre a existência comenta Marcos Bernardes de Mello (2007, p.99) "Ao sofrer a incidência da norma jurídica juridicizante, a parte relevante do suporte fático é transportada para o mundo jurídico ingressando no plano da existência. Neste plano, que é o plano do ser, entram todos os fatos jurídicos, lícitos ou ilícitos".

Tem-se que quando a norma jurídica é existente há de passar pelo plano da validade. A validade da norma jurídica, pode ser verificada conforme o critério formal, qual seja, se observou a forma e o procedimento adequado para que possa fazer parte do mundo jurídico e a validade material, que corresponde a sua legitimidade. 
O plano da eficácia, por sua vez é a parte do mundo jurídico onde as normas jurídicas produzem seus efeitos. A eficácia está diretamente relacionada à possibilidade de produzir consequências. Com relação a eficácia da norma jurídica Luís Roberto Barroso (2001, p.83) esclarece que "Tratando-se de uma norma jurídica, a eficácia jurídica designa a qualidade de produzir, em maior ou menor grau, os seus efeitos típicos [...]".

\subsection{Vinculação dos Particulares aos Direitos Fundamentais: um Problema de Eficácia Jurídica}

Estabelece Wilson Steinmetz que (2004, p. 39) "Na literatura constitucional, a vinculação dos particulares a direitos fundamentais aparece ora como problema de vigência de normas de direitos fundamentais, ora como problema de validez, ora como problema de efeito(s) e ora como problema de eficácia". Steinmetz rejeita a tese de que o problema da vinculação dos particulares seja um problema de validez ou vigência. Considera o autor que o problema se da no plano da eficácia somente.

A norma jurídica representa a valoração de fatos pela comunidade jurídica. Composto o seu suporte fático suficiente a norma jurídica incide decorrendo daí a sua jurisdicização. A incidência é o efeito da norma jurídica de transformar em fato jurídico a parte do seu suporte fático que o direito considerou relevante para ingressar no mundo jurídico.

A incidência da norma jurídica é posterior a sua vigência. A norma jurídica somente pode incidir após estar em vigor. Nesse contexto, distingue-se duas situações: norma existe simplesmente: a possibilidade de haver norma jurídica existente sem vigência se comprova pelos inúmeros casos de vacatio legis; norma existe com vigência, exemplo, quando tem a possibilidade de produzir efeitos específicos incidindo sobre o seu suporte fático.

O que distingue a norma jurídica simplesmente existente da norma vigente é a possibilidade de ser eficaz. Daí dizer que, a possibilidade de eficácia caracteriza a vigência. A validade seria a compatibilidade da norma jurídica inferior com a norma jurídica superior. $\mathrm{O}$ fundamento de validade formal e material de todo o ordenamento é a norma constitucional.

Nesse sentido, conclui Steinmetz (2004, p.42):

A eficácia, por sua vez, é o predicado da norma que se refere à capacidade técnica de produzir efeitos jurídicos. Assim, norma jurídica eficaz e aquela que pode ou deve ser aplicada porque está apita a produzir os efeitos técnicos previstos ou dela esperados. A eficácia não se confunde com a vigência e a validade. É possível a existência de norma jurídica vigente e 
válida e a validade. É possível a existência da norma jurídica vigente e válida sem eficácia e norma jurídica eficaz sem vigência (eficácia retroativa).

Portanto, a temática da vinculação dos particulares aos direitos fundamentais incide sobre o plano da eficácia da normas jurídicas, não tendo relações com a questão da validade ou vigência da norma. Mesmo porque, a eficácia, diferentemente da validade ou vigência, admite graus, os efeitos são produzidos em menor ou maior grau de eficácia.

\section{CONSIDERAÇÕES SOBRE A VINCULAÇÃO DOS PARTICULARES AOS DIREITOS FUNDAMENTAIS OU EFICÁCIA HORIZONTAL}

A ideologia liberal clássica manteve os direitos fundamentais restritos à relação do indivíduo para com o Estado, tem-se aqui o status negativo que pregava Jellinek. A função dos direitos fundamentais era meramente de defesa da esfera individual contra o poder soberano estatal.

De modo que, para proteger o homem dos perigos de um despotismo estatal cria-se um arcabouço jurídico de direitos que não podem ser corrompidos, são as denominadas liberdades negativas. Como observado, no estudo acerca do Estado Liberal, com a sociedade de massas, o sistema de liberdade negativas cria uma situação insustentável.

Com o advento do Estado social e o dever de prestação do Estado tem-se outros direitos, que passam a formar o arcabouço jurídico dos direitos fundamentais, exigindo uma atuação positiva do Estado. Mas ainda assim, a relação tradicional se mantém, sendo uma obrigação entre o Estado e o indivíduo, não adentrando a esfera privada.

Tal aspecto da relação entre o titular dos direitos fundamentais versus o Estado, seu único destinatário, caracteriza a chamada eficácia vertical dos direitos fundamentais. A relação é vertical, uma vez que se dá em dois planos distintos, semelhante ao binômio que vigora a ideologia burguesa clássica de separação entre Estado e Sociedade, a divergência se dá entre Estado detentor do poder de império e o indivíduo sem qualquer forma de se defender.

Essa separação entre Estado e Sociedade, entre espaço público e privado perde sentido e suas fronteiras não se tornam mais tão claras assim, com o advento do Estado Constitucional de Direito. Os dois campos da vida do ser humano, individual e público, se misturam. O 
homem não mais se contenta apenas que o Estado garanta a sua liberdade atuando de modo negativo, há a necessidade e o anseio por igualdade material.

Do mesmo modo se dá com a separação doutrinária entre direito público e direito privado. Essa distinção, se perde com o constitucionalismo de princípios, configurando o que Lorenzetti denomina de "Era da Desordem". A separação perfeita entre os âmbitos do direito público e do direito privado não mais existe como na modernidade, uma vez que há alterações nos pressupostos que originaram a divisão entre os dois campos.

Um dos fatores que causou essa clássica separação é segundo Lorenzetti a (2010, p.39) "[...] premissa de que o Estado é forte, está dotado de império, razão pela qual suas decisões são inatacáveis. Em sentido contrário, no direito privado existem sujeitos em situação de paridade, que tem relações horizontais".

Ocorre que, o Estado não é o único detentor do poder, surgem na sociedade civil elementos capazes de disputar e rivalizar com o poder estatal. Demandando, portanto, que a defesa dos direitos se não dê não apenas no âmbito da relação vertical entre indivíduo e poder público, mas também na relação de "igualdade" entre os particulares.

Considera Daniel Sarmento (2011, p.61) "Parece indiscutível que se a opressão e a violência contra a pessoa provêm não apenas do Estado, mas de uma multiplicidade de atores privados, presentes em esferas como o mercado, a família, a sociedade civil e a empresa [...]", então, nada mais natural que a proteção se estenda para além das ralações verticais indivíduoEstado.

Para o autor a vinculação desses direitos somente ao Estado é o resultado de uma ideologia liberal burguesa de legitimação da livre exploração na esfera privada. A liberdade protegida pelo Estado Burguês se torna mera liberdade de explorar o mais fraco, quando não vem acompanhada de igualdade material.

O Estado hodiernamente não tem, sé é que já teve, o monopólio do poder, aqui compreendido não somente como a mera força. Por conseguinte, passa-se a considerar que a esfera privada, não é livre de regulação por parte dos direitos fundamentais. Surge a necessidade do princípio da dignidade humana seja respeitado também em outras cearas.

Assim, o surgimento da sociedade de massas e o próprio enfraquecimento do Estado em razão da globalização, demonstram que associar o poder somente ao poder de império do poder público seja um erro. Nascem no âmbito nacional e principalmente internacional atores 
sociais capazes de oprimir o indivíduo e a dignidade da pessoa humana até mais do que o ente público.

Nesse contexto, justifica-se a aplicação dos direitos fundamentais à esfera privada. Contudo, os graus desta aplicação devem se dar nos mesmos moldes em que operam na eficácia vertical? Sendo esta uma das principais problemáticas da eficácia horizontal, a saber, qual o limite desta projeção de direito nas relações interprivas.

Daniel Sarmento alerta (2011, p.61):

$\mathrm{Na}$ verdade, não seria correto simplesmente transplantar o particular para a posição de sujeito passivo do direito fundamental, equiparando o seu regime jurídico ao dos Poderes Públicos, pois o indivíduo, diversamente do Estado, é titular de direitos fundamentais, e está investido pela própria Constituição em um poder de autodeterminação dos seus interesses. Uma equiparação do particular ao Estado, para fins de sujeição aos direitos fundamentais, tenderia a revelar-se autoritária, ao restringir em demasia a sua liberdade de fazer escolhas e agir de acordo com elas.

Destacam-se três fatores principais que envolvem essa problemática e que serão propriamente discutidos no próximo tópico: a ausência de previsão da vinculação nos textos constitucionais; o elevado grau de indeterminação das normas de direitos fundamentais; e a eliminação da autonomia privada.

\subsection{O Problema da Vinculação dos Particulares à Esfera Privada}

Dentre os diversos questionamentos sobre a aplicação dos direitos fundamentais nas relações privadas alerta-se para a ausência de previsão constitucional sobre o tema. De fato, a Constituição da República do Brasil de 1988 não traz nenhuma previsão expressa sobre o assunto.

Defensores da eficácia horizontal podem argumentar por uma interpretação a contrário sensu, que embora não exista nenhuma previsão constitucional, também não existe nenhuma proibição expressa, que impeça obrigar aos particulares a observarem os direitos fundamentais nas relações com outros particulares.

Sobre o assunto defende Fernando Martins (2011, p.234), que a Constituição não é feita "[...] separando Estado da sociedade e, por sua vez, a sociedade do indivíduo. Ao contrário disso, ela se afirma como norma de maior relevância e abstração e superioridade no ordenamento jurídico, englobando todos os atores institucionais (públicos e privados) e pessoais". 
Outro aspecto discutido é o elevado grau de indeterminação das normas de direitos fundamentais. Como visto, os direitos fundamentais são expressos em sua maioria em princípios jurídicos, que por sua estrutura normativa são maleáveis e apresentam alto grau de generalidade.

Longe de ser uma crítica à eficácia horizontal, tal característica permite maior flexibilidade na determinação da norma a ser aplicada ao caso concreto. Os direitos fundamentais não são absolutos e mediante a regra de ponderação podem vir a ceder a outro direito conforme o caso concreto.

É claro que, inegavelmente a partir do momento que valores são positivados no ordenamento jurídico por meio de princípios jurídicos, o momento de interpretação se torna mais complexo e abre espaço para maior "criação" do intérprete, do que somente a mera subsunção de regras.

Nesse caso, é procedente à crítica feita à teoria neoconstitucional de trazer maior subjetividade no momento da interpretação, correndo-se o risco de permitir que o intérprete traga para dentro da norma as suas experiências pessoais. Tendo-se o risco de serem produzidas decisões solipsistas.

A possibilidade dos direitos fundamentais se projetarem para uma relação interprivadas ainda é questionada quanto a eliminação da autonomia, com a consequente colonização da constituição pelo direito privado ou uma panconstitucionalização. Nesse sentido, preocupa-se que a constituição eclipse o direito privado e o âmbito de livre determinação dos indivíduos.

O grande embate aqui é entre os princípios da autonomia privada e a dignidade da pessoa humana. Tal conflito deve ser resolvido mediante o caso concreto com a aplicação da regra de ponderação. Mas fora de dúvidas que, a liberdade individual de ingerência da própria vida é um valor que não pode ser eclipsado.

Contudo, a experiência do Estado Liberal ensina que só existe verdadeira liberdade, quando há igualdade material. E as condições sociais e econômicas sempre demonstraram que os homens não possuem igualdade de condições para o seu livre desenvolvimento. Assim sendo, somente a justiça do caso concreto para indicar a solução mais adequada.

Ademais, não se pode negar o caráter da supremacia da constituição, fundamento de validade de todas as outras normas. E ao se positivar os direitos fundamentais na constituição, 
torna-os como necessários na averiguação da validade de leis infraconstitucionais e atos administrativos, expandindo-se também para as relações interprivadas.

\subsection{Breve Histórico da Aplicação da Vinculação dos Particulares aos Direitos}

\section{Fundamentais}

A discussão aqui tratada sobre a vinculação dos particulares aos direitos fundamentais tem como marco o caso emblemático ocorrido na República Federal da Alemanha. O paradigma é o Caso Lüth julgado em 1958, que iniciou a discussão sobre o Drittwirkung der Grundrechte.

No caso emblemático Erich Lüth, judeu e presidente de clube de imprensa de Hamburgo, organizou um boicote ao filme "Amada Imortal" produzido por Veit Harlan, alemão diretor cinematográfico. A grande questão era que Harlan era reconhecidamente nazista tendo ajudado na divulgação das ideologias nazistas durante a era Hitler.

Nesse sentido, Lüth organizou uma campanha contra o filme, conclamando os cidadãos alemães a não assistirem. Como resultado o filme foi um fracasso, e Harlan processou o judeu pelo prejuízo causado pela sua campanha. O caso chegou ao Tribunal Constitucional Alemão, que em decisão de repercussão mundial, decidiu pela condenação de Lüth pelos prejuízos causados, com fundamento que os direitos fundamentais não eram somente aplicados na relação indivíduo e Estado, mas também entre particulares.

O debate não se restringiu aos alemães. Nos Estados Unidos, o tema da vinculação dos particulares é altamente debatido, no país vigora a concepção os direitos fundamentais devem ser aplicados somente na relação entre Estado e indivíduo, principalmente por causa da state action doctrine.

Sarmento ( 2011, p.64) explica

No cenário norte-americano tem prevalecido a visão de que, em regra geral, os direitos fundamentais positivados na Constituição não se estendem às relações privadas. É praticamente um axioma do Direito Constitucional norteamericano, quase universalmente aceito tanto pela doutrina como pela jurisprudência, a ideia de que os direitos fundamentais, previstos no Bill of Rights da Constituição daquele país, impõem limitações apenas para os Poderes Públicos e não atribuem aos particulares direitos frente a outros particulares com exceção apenas da $1^{\mathrm{a}}$ Emenda, que proibiu a escravidão. Trata-se da chamada teoria da state action. 
A doutrina da state action tem sido relativamente temperada segundo Sarmento pela ( 2011, p.64) "public function theory, segundo a qual quando particulares agirem no exercício de atividades de natureza tipicamente estatal, estarão também sujeitos às limitações constitucionais".

No Brasil a questão é amplamente discutida na doutrina e jurisprudência. De modo que, passa-se a analisar dois casos emblemáticos julgados pelo Supremo Tribunal Federal, para tratar da questão. Ambos os casos são importantes, pois demonstram a fixação do entendimento da corte suprema brasileira sobre o assunto.

O primeiro caso é o RE 160.222/RJ de Relatoria do Min. Sepúlveda Pertence, julgado em 1995, que trata da revista íntima de funcionárias que trabalhavam em empresa privada. O gerente da entidade privada, a qual comercializava lingerie, exigia que as funcionárias deveriam se despir para demonstrar que não estavam furtando peças de roupa íntima. Discutiu-se sobre a configuração do crime de constrangimento ilegal.

Segue ementa do referido caso:

E M E N T A - I. Recurso extraordinário: legitimação da ofendida ainda que equivocadamente arrolada como testemunha -, não habilitada anteriormente, o que, porém, não a inibe de interpor o recurso, nos quinze dias seguintes ao término do prazo do Ministério Público, (STF, Sums. 210 e 448).

II. Constrangimento ilegal: submissão das operárias de indústria de vestuário a revista íntima, sob ameaça de dispensa; sentença condenatória de primeiro grau fundada na garantia constitucional da intimidade e acórdão absolutório do Tribunal de Justica, porque o constrangimento questionado a intimidade das trabalhadoras, embora existente, fora admitido por sua adesão ao contrato de trabalho: questão que, malgrado a sua relevância constitucional, já não pode ser solvida neste processo, dada a prescrição superveniente, contada desde a sentença de primeira instância e jamais interrompida, desde então. (RE $\mathrm{n}^{\circ}$ 160.222-RJ, Rel. Min. Sepúlveda Pertence, DJ de 01/09/1995)

O segundo caso é o Recurso Extraordinário 201.819/RJ, julgado em 2005 pela Segunda Turma do Supremo Tribunal Federal. Debatia-se sobre a exclusão de membro de sociedade privada sem a possibilidade de sua defesa. Ou seja, o direito de ampla defesa consagrado no art. $5^{\circ}$ da Constituição de 1988 poderia ser invocado frente a decisão de um entidade privada e não um órgão da administração pública.

Ambos os casos são simbólicos para demonstrar a jurisprudência da corte nacional no sentido de reconhecer a chamada eficácia horizontal ou eficácia externa dos direitos fundamentais. Demonstrando que, a questão principal não é se existe essa eficácia, mas em qual grau ela deve ocorrer. 


\subsection{As Teorias da eEicácia Direita e Eficácia Imediata}

Quando se fala da vinculação dos particulares aos direitos fundamentais uma das maiores problemáticas da questão revela-se quanto a verificar o limite ou extensão dessa vinculação. Nesse sentido, duas teorias merecem ser estudas: eficácia direita ou imediata; e eficácia indireta ou mediata.

Há ainda, uma terceira, denominada como teoria dos deveres de proteção. Essa tese é desenvolvida pelo estudioso alemão Claus-Wilhelm Canaris. Contudo, apesar de demonstrar uma terceira possibilidade em ralação às duas anteriores, é considerada por muitos, uma variação da eficácia mediata.

Com relação às teorias observa-se que excluem-se da análise aqueles direitos que tem como único destinatário o Estado (dotados de unidirecionalidade). Trata-se na presente pesquisa apenas dos direitos bidimencionais, ou seja, aqueles direitos que tem como destinatário a sociedade e o poder público. São exemplos de direitos fundamentais unidirecionais principalmente os direitos políticos (direito de votar e ser votado), e mesmo garantias como o Habeas Corpurs e o mandado de segurança.

\subsubsection{Teoria da Eficácia Indireta ou Mediata}

Conforme a teoria da eficácia mediata ou indireta, a aplicação dos direitos fundamentais nas relações interprivadas dar-se de dois modos: primeiramente pelo esforço do Poder Legislativo, no momento do exercício de sua função típica, cumpra dois papéis: se abster de violar esses direitos e promover a devida proteção necessária.

Em segundo lugar essa teoria demanda que, o judiciário, ou melhor, o magistrado no exercício do processo hermenêutico e na aplicação da norma jurídica ao caso concreto também renuncie de violar tais direitos e que prolate suas decisões garantindo a sua devida proteção.

A teoria irá negar a aplicação direta por respeitar a esfera de autonomia da vontade, assim como, visa evitar a erradicação do direito privado pela constituição. Ademais, diferentemente da relação entre Estado e indivíduo, na relação entre particulares todos são sujeitos de direitos fundamentais, seja pessoa natural ou jurídica ou mesmo grupos sociais. 
Deste modo, como não podem tais direitos ser aplicados diretamente da constituição para as relações entre particulares. A operabilidade, a incidência se dará por meio, principalmente, de dois instrumentos, os quais o legislador fará uso: as cláusulas gerais e os conceitos jurídicos indeterminados.

Contudo, a grande crítica reside justamente no fato de que na ausência de um desses instrumentos (clausulas gerais e/ou conceitos indeterminados) não se teria como aplicar os direitos fundamentais nas relações entre particulares. Nesses casos, ter-se-ia uma lacuna no ordenamento, pois inexiste norma ou mecanismo infraconstitucional, que garanta a devida proteção à dignidade humana.

Sarmento (2011, p.67) acrescenta "[...] a aplicação direta dos direitos fundamentais nas relações privadas importaria na outorga de um poder desmesurado ao Judiciário, tendo em vista o grau de indeterminação que caracteriza as normas constitucionais consagradoras desses direitos". E para evitar essa subjetividade, tal teoria argumenta apenas a favor de uma eficácia horizontal mediata e, portanto, mais comedida dos direitos fundamentais nesse tipo específico de relação.

\subsubsection{Teoria da Eficácia Direta ou Imediata}

Segundo a teoria da eficácia direta ou imediata, os direitos fundamentais devem ser aplicados diretamente não apenas na relação indivíduo/Estado, mas também nas relações entre particulares. Tal teoria foi defendida na Alemanha, na década de 1950, por Hans Carl Nipperdey que apregoava a eficácia externa desses direitos incidindo diretamente, sem qualquer necessidade de intervenção do legislador.

Segundo Daniel Sarmento (2011, p.71) "Embora minoritária no cenário germânico, a tese da eficácia horizontal imediata tem ampla penetração na doutrina de outros Estados europeus, como Espanha, Portugal e Itália". Para o alemão os direitos fundamentais seriam dotados de eficácia erga omnes perante o Estado e a sociedade.

Assim, a teoria permite que se extraia os direitos fundamentais da própria constituição, sem que haja um regramento específico perante qualquer destinatário, independentemente que seja pessoa privada. A vantagem da presente teoria em relação a anterior é que na ausência de instrumentos infraconstitucionais que possibilitem a aplicação dos direitos fundamentais, esses poderão incidir diretamente da constituição, a qualquer quer tipo de relação. 
Uma das críticas a essa doutrina é que conferiria grande poder ao magistrado, e ademais comprometeria a existência de decisões democráticas. Julgamentos semelhantes também são feitos à teoria neoconstitucional, e contra os quais é necessário fazer uma ressalva.

Como visto no primeiro capítulo, na formação do Estado liberal constituiu-se a noção de que o Legislativo era o órgão de representatividade, visto que responsável pela elaboração da lei, sendo está a máxima expressão da vontade geral. Esta concepção sobre o Legislativo como representante da soberania do povo baseia-se na doutrina de Rousseau.

Entrementes, o filósofo francês sempre combateu a democracia representativa, sendo favorável à democracia direta. Contudo, na prática altera-se a doutrina de Rousseau e funda-se o princípio democrático na representatividade por meio do parlamento.

Contudo, com a queda do fetichismo legal, principalmente pela concepção que a maioria e democracia não são sinônimos e que muitas vezes a dita "vontade geral" nada mais é do que interesses de grupos setoriais, passa-se a questionar o argumento democrático típico do liberalismo.

No Estado Constitucional, a lei não goza mais do mesmo status, pois passa agora a se submeter à constituição, a qual em seu conteúdo apresenta um conjunto inviolável de direitos, que não podem ser alteradas nem mesmo pelo legislador infraconstitucional. E ao Judiciário é conferida a guarda e proteção dessa lei fundamental.

Partilhando da mesma opinião complementa Sarmento (2011, p.72):

Tampouco se pode acusar a doutrina da eficácia imediata dos direitos fundamentais nas relações privadas de incompatível com o princípio democrático, por atribuir poder em demasia ao Judiciário, em detrimento do legislador. Isto porque, em primeiro lugar, a proteção de direitos fundamentais, no mais das vezes, não prejudica a democracia, mas antes assegura as condições necessárias ao seu bom funcionamento. Ademais, a maior parte dos adeptos desta teoria reconhece que, diante da existência de lei disciplinando a questão subjacente ao conflito privado, deve o Judiciário aplicar a norma vigente - e não dar ao caso a resposta que pareça mais justa a cada magistrado -, podendo afastar-se da solução preconizada pelo legislador tão somente quando concluir que esta se afigura incompatível com a Constituição.

Nesse contexto, o parlamento encontra-se limitado pelo legislador constituinte. Tal concepção, longe de ferir o processo democrático, o aprimora, pois garante a proteção dos direitos das minorias, que não mais está sujeito as possíveis alterações de humores e inflexões 
das maiorias. Outrossim as decisões judiciais não são antidemocráticas, ao contrário visam cumprir democraticamente as determinações constitucionais.

\subsubsection{Teoria dos Deveres de Proteção}

A teoria dos deveres de proteção é uma teoria intermediária entre as duas anteriores, sendo mesmo considerada uma variação da teoria da eficácia indireta. $\mathrm{O}$ seu principal defensor é o alemão Claus-Wilhelm Canaris, que considera que dos direitos fundamentais vinculam diretamente apenas o Estado.

O autor considera que a eficácia dos direitos fundamentais tem duas dimensões: defensiva, a saber, proíbe o legislador e o magistrado de violarem a constituição ("proibição de intervenção"); e a protetiva, deve o poder público proteger os direitos fundamentais individuais e sociais de qualquer ataque por parte de outros entes, sejam este públicos ou privados ("imperativo de tutela" ou "imperativo de proteção")

Percebe-se que a teoria seria mais uma variação da teoria da eficácia indireta, possuindo a vantagem de visar proteger não só os direitos fundamentais, mas também a autonomia privada e a independência do direito privado em relação à constituição e ao direito constitucional.

Sobre a doutrina de Canaris, explica Sarmento (2011, p.74):

Entende Canaris que é possível analisar a influência dos direitos fundamentais sobre o Direito Privado em diferentes planos. O primeiro deles é o da vinculação do legislador do Direito Privado aos direitos fundamentais. Esta vinculação, para ele, é direta e imediata, e decorre não só de expressa previsão no texto constitucional germânico (art. $1^{\circ}, \mathrm{n}^{\circ} 3$, da Lei Fundamental), como também do próprio princípio da supremacia da Constituição. Assim, as normas editadas no âmbito do Direito Privado não só não podem violar os direitos fundamentais dos particulares, como devem também proporcionar uma proteção adequada a estes direitos em face da conduta de outros atores privados.

Portanto, para Canaris há uma vinculação p ositiva e negativa do poder público aos direitos fundamentais. Negativamente (obrigação de não fazer) deve o Estado se abster de violar. Positivamente (obrigação de fazer) deve o Legislativo e o Judiciário impedir que outros violem esses direitos.

\subsubsection{Teoria da Eficácia Diagonal dos Direitos Fundamentais}


Sergio Gamonal Contreras traz uma nova nomenclatura para a vinculação dos particulares aos direitos fundamentais, a saber, a eficácia diagonal dos direitos fundamentais. Segundo o professor chileno há casos em que os particulares se encontram em posições jurídicas extremamente desiguais, de modo que, não se trata de uma relação de horizontalização, mas sim diagonal.

Seria o caso de certas relações entre empregado e empregador, em que o último encontrase numa posição superior, configurando, portanto, uma relação diagonal. A teoria é considerada como reformulação moderna da eficácia horizontal, contudo ainda modestamente empregada.

Tem-se exemplo na jurisprudência nacional a aplicação da seguinte terminologia no TRT-1 - Recurso Ordinário - RO 7524420125010342 RJ (TRT-1), publicado em 16 de setembro de 2013.

\section{CONSIDERAÇÕES FINAIS}

O liberalismo consagrou em seu bojo o surgimento da proteção dos direitos fundamentais das liberdade negativas contra o Estado. Marcadamente a relação entre indivíduo e Estado era de mero de antagonismo. O Estado social modificou a relação, que era meramente de não interferência do poder público na esfera de ingerência privada, para uma relação de dever de prestação por parte do Estado.

Nesse contexto, o Estado apresenta deveres de abstenção e prestação, os quais deve cumprir para garantir a existência de um "mínimo existencial" desses direitos, principalmente no que tange aos direitos sociais, tais como direito à saúde, educação, moradia, trabalho, previdência, etc.

A temática da vinculação dos particulares aos direitos fundamentais se desenvolve no como um problema de eficácia jurídica, com o conflito, especificadamente, de dois princípios jurídicos: autonomia da vontade e dignidade da pessoa humana. As teorias que defendem a vinculação dos particulares aos direitos fundamentais se baseiam na noção de que o âmbito privado não é espaço de livre ingerência dos direitos fundamentais, ao contrário, esses devem ser preservados, frente a existência de atores sociais capazes de oprimir o indivíduo tanto quanto o Estado. 
Dividem-se as teorias quanto ao limite ou extensão da aplicação desses direitos nas relações interprivadas. A teoria da eficácia direta é vantajosa por permitir a aplicação imediata dos direitos fundamentais da constituição para o caso concreto. A crítica estaria no risco de eclipsar a autonomia da vontade.

A teoria da eficácia indireta tenta preservar a autonomia da vontade ao admitir a vinculação somente por meio das clausulas gerais e dos conceitos jurídicos indeterminados. A teoria dos deveres de proteção de Canaris apresenta-se como uma variação mais efetiva dessa teoria.

Independente de qual teoria se opte por filiar considera-se na presente pesquisa, que quando se trata de direitos fundamentais a melhor solução será adotar aquela que o caso concreto demanda. O caso concreto, portanto, é quem dirá qual a escolha deve ser feita pelo operador do direito.

\section{REFERÊNCIAS}

BOBBIO, Norberto. A Era dos Direitos. Rio de Janeiro: Editora Elsevier 2004.

BONAVIDES, Paulo. Do Estado Liberal ao Estado Social. $11^{\circ} \mathrm{ed}$. São Paulo: Malheiros, 2013.

CATTONi DE OlIVEIRA, Marcelo Antônio. Teoria da Constituição. $1^{\circ}$ ed. Belo Horizonte: Initia Via, 2012

COMPARATO, Fábio Konder. A afirmação histórica dos direitos humanos. 5 ed. São Paulo: Saraiva, 2007.

DIMOULIS, Dimitri; MARTINS, Leonardo. Teoria geral dos direitos fundamentais. São Paulo: Revista dos Tribunais, 2011.

FERRAJOLI, Luigi. Por uma teoria dos direitos e dos bens fundamentais. trad. Alexandre Salim, Alfredo Copetti Neto, Daniela Cadermatori, Hermes Zaneti Júnior, Sérgio Cadermatori. Porto Alegre, Livraria do Advogado, 2011.

FERRAJOLI, Luigi. Constitucionalismo Garantista e Neoconstitucionalista. In Anais do IX Simpósio de Direito Constitucional da ABDConst. Curitiba: ABDConst., 2011. 
FERREIRA FILHO, Manoel Gonçalves. Direitos humanos fundamentais. - $9^{a}$ ed. São Paulo: Saraiva, 2007.

KRIELE, Martins. Introdução à teoria do estado: os fundamentos históricos da legitimidade do estado constitucional democrático. trad. Urbano Carvelii. Porto alegre: Sergio Antonio Fabris, 2009.

LORENZETTI, Ricardo Luis. Teoria da decisão judicial: fundamentos do direito. trad. Bruno Miragem; Cláudia Lima Marques. São Paulo: Revista dos Tribunais, 2010.

MARTINS, Fernando Rodrigues. Princípio da justiça contratual. 2. ed. São Paulo: Saraiva, 2011.

MENDES, Gilmar Ferreira; COELHO, Inocêncio Mártires; BRANCO, Paulo Gustavo Gornet Branco. Curso de Direito Constitucional. $8^{\circ}$ ed. São Paulo, Saraiva, 2009.

SARLET, Ingo Wolfgang. A eficácia dos direitos fundamentais: uma teoria geral dos direitos fundamentais na perspectiva constitucional. $10^{\circ}$ ed. Porto Alegre: Livraria do Advogado, 2010.

SARMENTO, Daniel; GOMES, Fábio Rodrigues. A eficácia dos direitos fundamentais nas relações entre particulares: o caso das relações de trabalho. Revista do Tribunal Superior do Trabalho, São Paulo, v. 77, n. 4, p. 60-101, out./dez. 2011.

STEINMETZ,Wilson. A vinculação dos particulares a direitos fundamentais, São Paulo: Malheiros, 2004.

TEPEDINO, Gustavo. A incorporação dos Direitos Fundamentais pelo ordenamento brasileiro: sua eficácia nas relações jurídicas privadas. In: Temas de Direito Civil. Tomo III. Rio de Janeiro: Renovar, 2009. 